\title{
ASYMPTOTIC GENERALIZED VALUE DISTRIBUTION OF SOLUTIONS OF THE SCHRÖDINGER EQUATION
}

\section{Y. CHRISTODOUlides}

Abstract. The theory of generalized value distribution for boundary values of Herglotz functions is applied to the Weyl-Titchmarsh $m$-function in Sturm-Liouville theory, and leads to a description of generalized value distribution of the logarithmic derivative $-\frac{v^{\prime}}{v}$, where $v$ is a basic solution of the Schrödinger equation.

Mathematics subject classification (2010): 30D35, 34M30.

Keywords and phrases: Asymptotic generalized value distribution, Herglotz functions.

\section{REFERENCES}

[1] N. I. Akhiezer And I. M. Glazman, Theory of Linear Operators in Hilbert space I, Pitman, London, (1981).

[2] S. V. Breimesser And D. B. Pearson, Asymptotic value distribution for solutions of the Schrödinger equation, Math. Phys., Anal. and Geom., Vol. 3, 4 (2000), p. 385-403.

[3] Y. T. Christodoulides And D. B. Pearson, Generalized value distribution for Herglotz functions and spectral theory, Math. Phys., Anal. and Geom., Vol. 7, 4 (2004), p. 309-331.

[4] Y. T. Christodoulides And D. B. Pearson, Spectral theory of Herglotz functions and their compositions, Math. Phys., Anal. and Geom., Vol. 7, 4 (2004), p. 333-345.

[5] E. A. Coddington And N. Levinson, Theory of Ordinary Differential Equations, McGraw-Hill, New York, (1955).

[6] G. Herglotz, Über potenzreihen mit positivem, reelem Teil in Einheitskreis, Sächs. acad. Wiss. Leipzig, Vol. 63, (1911), p. 501-511.

[7] D. B. Pearson, Value distribution and spectral theory, Proc. Lond. Math. Soc., Vol. 68, 3 (1994), p. $127-144$.

[8] D. B. Pearson, Quantum Scattering and Spectral Theory, Academic Press, London, (1988). 